\title{
Capabilities for smart services in manufacturing companies
}

\author{
Lucie Kaňovská \\ Institute of Management, Faculty of Business and Management, Brno University of \\ Technology
}

\begin{abstract}
A lot of manufacturing companies supply their tangible products accompanied with suitable services to their customers. Currently also smart services are being added to their service offerings. Applying the change toward smart services is not easy, especially in SMEs where many of businesses fight with lack of money, insufficient digital technologies or unskilled employees. The aim of the paper is focused on significant capabilities of SMEs, which are crucial for smart service provision in manufacturing companies. To fulfil the research aim, a qualitative multi-case study was conducted among seven Czech electrotechnical SMEs, which have already started with smart service development. The findings show that respondents consider wide range of possible capabilities, which could be divided into three main categories, such as technical equipment, internal readiness and knowledge and involvement of customers.
\end{abstract}

Keywords: capabilities, servitization, smart services, SMEs, electrotechnical manufacturers.

\section{Introduction}

During last years more and more manufacturers try to transform their pure product offering to offering focused more on services. They add services to their product offering to be able to satisfy their customers with better complexity. Moreover, services included in product offering can help to gain and held their position on the markets. Many manufactures perceive service provision as a significant competitive advantage. Therefore, services are not seen only as add-ons to the product, but become the center of the total offering, with products as add-ons to the services (Gebauer, Gustafsson and Witell, 2011). Service differentiation in manufacturing takes advantage of the strategic, financial and marketing opportunities. 
Servitization means a transformation of manufacturers to solution providers by adding value to core products through services (Baines et al., 2017; Wise and Baumgartner, 1999) and was first mentioned by Vandermerwe and Rada (1988). Due to servitization, the focus shifts more from a product-centered focus towards the service component (Brax and Jonsson, 2009). Services and integrated solution can also support to gain new sources of competitive advantage and value generation (e. g. Brax and Jonsson, 2009; Oliva and Kallenberg, 2003; Wise and Baumgartner, 1999).

Allmendinger and Lombreglia (2005) state that "Soon, it will not be enough for a company to offer services; it will have to provide 'smart services'. Smart services as often seen as one of the enablers of servitization (e.g. Grubic and Peppard, 2016; Neu and Brown, 2008; Oliva and Kallenberg, 2003). "Smart services are technologically-mediated services actively delivered by the provider through accessing a remote asset and exchanging data through built-in control and/or feedback devices" (Klein (2017). Smart service is the application of specialized competences, through deeds, processes, and performances that are enabled by smart products (Beverungen, Matzner and Janiesch, 2017).

A lot of opposing definitions and terminologies are used for smart services (Klein, 2017), such as 'teleservice' (Borgmeier, 2002; Küssel, Liestmann, Spiess and Stich, 2000), 'telemaintenance' (Garcia, Guyennet, Lapayre and Zerhouni, 2004), 'telematics' (Chatterjee, Greenberg, Jones, Kaas and Wojcik, 2001), 'e-service' (Rowley, 2006), 'e-maintenance' (Levrat, Iung and Crespo Marquez, 2008) or some variations, combinations or adaptions using the term 'remote', such as 'RRDM (Remote Repair, Diagnostics and Maintenance)' (Biehl, Prater and McIntyre, 2004). According to Klein (2017), the term 'smart service' has gained popularity more recently. For this paper, the term 'smart service' is used.

Many benefits could be obtained from smart services offering for manufacturers as service providers and also for their customers. Smart services are more competitive, offer new sources of revenue, higher margins, and considerable cost savings (Küssel et al., 2000). Not only monetary benefits could be use from smart services, but also variety of non-monetary benefits, such as the opportunity to learn from customers, establishing a basis for research and development, sales or marketing activities (Laine, Paranko and Suomala, 2010). Consequently, companies can also profit from a significant strategic position in B2B and B2C contexts (Wünderlich et al., 2015). Porter and Heppelmann (2014) recapitulate the position of smart services: "[They] offer exponentially expanding opportunities for new functionality, far greater reliability, much higher product utilization, and capabilities that cut across and transcend traditional product boundaries". Benchmarks show that companies, which deliver smart services, get more than $50 \%$ of revenue and $60 \%$ of margins from services than from product sales (Allmendinger and Lombreglia, 2005).

Customers can benefit from smart services in the meaning that "the value of smart services is in removing unpleasant surprises from their lives" (Allmendinger and Lombreglia, 2005). The profits could be gathered in reduction of machine downtimes, optimized scheduling of maintenance, more safety, improved information flow and 
transparency as well as a reduction of labor costs and creation of a better work environment (Lee, Kao and Yang, 2014).

An organization's overall portfolio of capabilities can be seen in two levels (Winter, 2003). Operational and other ordinary capabilities are at the base level, such as routine activities, administration, and basic governance. The level of dynamic capabilities is above the base level. Dynamic capabilities can be split into "microfoundations" and "higher-order capabilities" (Teece, 2007). Microfoundations contain the adjustment and recombination of a firm's existing ordinary capabilities and also contain the development of new capabilities. They are second-order dynamic capabilities that involve new product development, expansion into new sales territories, the assignment of product mandates across divisions in the big corporations, and other activities that establish smart managerial decision making under uncertainty. The high-order dynamic capabilities by which management, supported by processes in company, senses possible ways for future, formulates business models to seize new or changed opportunities, and the best structures for the company based on its existing for and the new strategies for the future (Teece, 2018). Top management is (or should be) most focused on the high-order dynamic capabilities, because they are most appropriate for the innovation and selection of business models that address problems and opportunities the company is attempting to solve or exploit (Teece, 2018).

Marquardt (2017) considers the main challenge for businesses in competitive markets in the following areas:

- flexibility,

- progressiveness,

- be a visionary,

- be at the height of evolution.

The factors that enable the benefits of smart services to be realized are these:

- skills, experience and knowledge,

- support from customers and from other complementary data sources, processes and structures,

- operating centers,

- historical data,

- the presence of internal knowledge and skills (Grubic and Peppard, 2016).

According to the report "Manufacturing 2020" (Manufacturer, 2018), it is necessary for the company to be able to look to 2020 . It is useful to be, at the same time, able to ensure effective business in the future. Furthermore, the report recommends that the customer 
should always be at the center of the digital strategy. It is also ideal to minimize internal barriers as much as possible to provide customized products and services to the customer.

It is also necessary to identify new opportunities for maintaining and expanding the business and to uncover possible rapid challenges (e.g. according to Table 1) that are associated with market competition. In the case of smart services, big data, smart platforms and their management are often mentioned as a future competitive advantage.

Tab. 1: Challenges for smart services

\begin{tabular}{|l|c|}
\hline Challenges & Prerequisites \\
\hline Lack of standards and cooperation & Intelligent data collection platforms \\
\hline Data ownership, security and privacy concerns & Big data, smart data \\
\hline $\begin{array}{l}\text { Large investments and uncertain return on } \\
\text { investment (ROI) }\end{array}$ & $\begin{array}{c}\text { IT infastructure } \\
\text { pensors and business intelligence for collection and data }\end{array}$ \\
\hline Technology and data analytics deficits & Data analytics, data mining skills \\
\hline Lack of experienced staff and knowledge & Visionary leadership, descriptive approach \\
\hline Lack of courage management to change & Determining possible sales strategies \\
\hline Missing vision and business models & \\
\hline
\end{tabular}

Source: Marquardt (2017).

The aim of the paper is to find out significant capabilities of SMEs, which are crucial for smart service provision in the manufacturing companies.

\section{Methods and Data}

Smart services based on smart products discussed in the paper are a very innovative topic, which is quite new in the research field and still open to new investigations. To find out more about smart services provided by manufacturers, a qualitative research was conducted as a multi-case study among seven SMEs electrotechnical companies, South Moravian Region. The research explored how smart services are provided by current manufacturing SMEs. The in-depth interviews investigated following aspects: type of smart products and smart services, the length and way of smart service provision, customer perception of smart services, the reasons for starting with smart service provision, the capabilities for smart service provision, the benefits gained from smart services, barriers connected to smart service provision, gathering and using the data gained from smart services, specifics of Czech industrial market, collaboration with other firms and "learnings" for other firms which want to start with smart services. The in-depth interviews were important to learn more about the current situation of smart service 
offering in electrotechnical companies and understand to complex situation of smart service provision.

The multi-case approach delivered analytical benefits by enabling comparison and contrast of the results to get the distinction of case specific findings as well as some general phenomena. The part of the study focusing on capabilities for smart service provision was used for the purpose of this paper.

The qualitative research concluded only electrotechnical SMEs, where producers are often very familiar with smart service provision. Their products enable to include smart services to their total offering and are often one of the key characteristics of them. All respondents operate in the same industry, as was mentioned before, but they offer a wide scope of products and services to their customers with varying degrees of service orientation. The different level and wide range of smart services provides valuable insights into smart services in SMEs in different contexts. The following smart services are provided remote monitoring, control and diagnostics, remote repairs, preventive and predictive maintenance.

The case companies for qualitative research were selected based on purposive sampling (Eisenhardt and Graebner, 2007). The details of the case companies are described in Table 1. Three companies were found as the members of Electrotechnical Association of the Czech Republic (https://www.electroindustry.cz/). Four companies providing smart services were detected from the previous research, which was held in sixty electrotechnical SMEs companies in the Czech Republic, South Moravian Region (CZNACE 26 and CZ-NACE 27). The respondents participating in the research were directors or managers of companies producing electrical engineering equipment in the Czech Republic.

The data were collected from February to November 2014. Each interview lasted from 50 to 100 minutes and was performed on site, which gave a chance to tour each company and get a sense of the work environment. All interviews were recorded and transcribed. After selecting the case companies, semi-structured interviews with predefined themes were conducted. The interview consisted of open-ended questions, which were based on the literature review. All interviews were conducted face-to-face. Open coding was used to organize the data and convert them to discrete thematic blocks. 
Table 2 shows main information about case companies. For this paper only basic information was chosen.

Tab. 2: Case company description

\begin{tabular}{|c|c|c|c|c|}
\hline Firm & Respondents & $\begin{array}{l}\text { Number of } \\
\text { employees }\end{array}$ & Company history & $\begin{array}{c}\text { The length of smart } \\
\text { service provision in years }\end{array}$ \\
\hline A & Owner & 15 & more than 5 years & 1 \\
\hline $\mathrm{B}$ & Product manager & 50 & more than 5 years & 1 \\
\hline $\mathrm{C}$ & Owner & 10 & more than 5 years & 2 \\
\hline $\mathrm{D}$ & Owner & 4 & less than 2 years & 2 \\
\hline$E$ & Owner & 25 & less than 2 years & 2 \\
\hline $\mathrm{F}$ & Owner & 148 & more than 5 years & 2 \\
\hline$G$ & Product Manager & 170 & more than 5 years & More than 2 \\
\hline
\end{tabular}

Source: Author.

The respondents from electrotechnical companies were mostly owners who were very keen on to develop smart services more deeply. Companies were mostly established more than five years ago, and they have started with smart service provision mostly two years ago. All of them agreed that smart services are the future of manufacturing.

\section{Results}

The research question (RQ) was formulated in the following statement: RQ: Which capabilities are important for smart service provision in electrotechnical companies?

The question for respondents during in-depth interviews was stated as "Which capabilities are important for smart service provision in your company? " and obtained broad range of answers. Respondents answered in terms of technical equipment (technology, interconnection, communication protocols), in terms of internal readiness (such as innovation, knowledge, financial resources, active employees) and also with regard to the importance of knowledge and customer involvement (more in Table 3 and Picture 1). The most topical response is from company $\mathrm{G}$, where the respondent stated that their multidisciplinarity allows them to provide smart services. 
Tab. 3: Capabilities for smart service provision according to case companies

\begin{tabular}{|l|l|}
\hline Firm & Capabilities for smart service provision \\
\hline A & $\begin{array}{l}\text { Ability for innovations, technical knowledge and equipment, proactive management and free financial } \\
\text { resources. }\end{array}$ \\
\hline B & Sufficient knowledge and storage capacity. \\
\hline C & Good knowledge of technology and customer needs. \\
\hline D & Have customers, store and market information. Be enthusiastic. Have education in electrotechnics. \\
\hline E & Enthusiastic employees (co-partners), involvement of customers. \\
\hline F & Connection using public IP addresses, supported communication protocols. \\
\hline G & Multidisciplinarity. \\
\hline
\end{tabular}

Source: Author.

Picture 1 shows capabilities for smart service provision divided into three main categories, which were mentioned during interviews by respondents. The categories were created by grouping similar answers together to gain a list of main fields based on respondent responses, that are listed in the Table 3.

Pic. 1: Capabilities for smart service provision

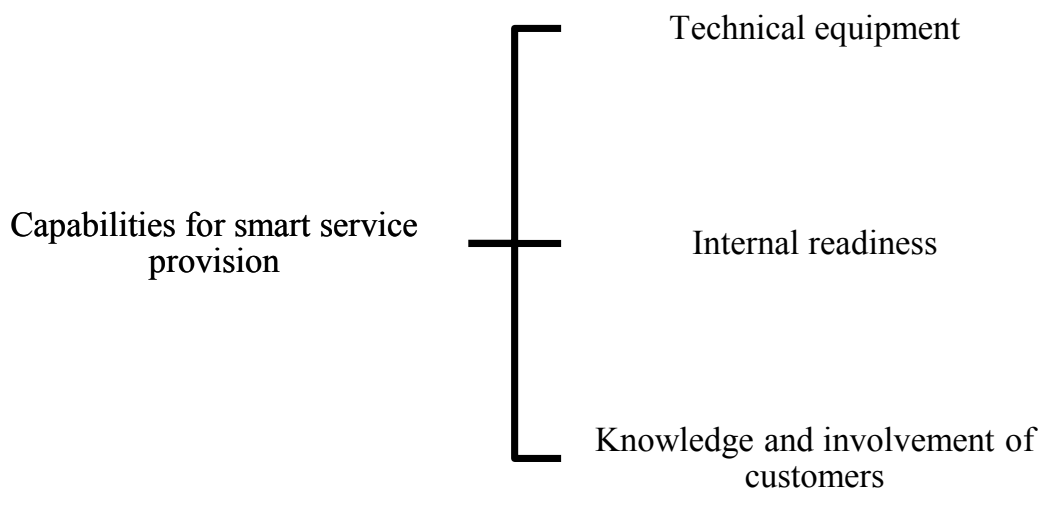

Source: Author.

Three main categories of capabilities for smart service provision according to respondents are: technical equipment, internal readiness and knowledge and involvement of customers. The most often mentioned was category related to technical equipment. During interviews was heard often that technical equipment is the first and most important capabilities for starting with smart service provision. However, the limited number of cases discourages a consistent generalization of the findings achieved so far, that will have to be confirmed by further investigations. 


\section{Discussion}

The aim of this paper has been an investigation of capabilities for smart service provision in manufacturing companies. The qualitative research was held among seven electrotechnical companies in the Czech Republic, South Moravian Region. A research question was formulated in this paper to understand which capabilities are important for smart service provision in electrotechnical companies.

\section{Theoretical Implications}

According to the research mentioned in this paper, respondents consider wide range of possible capabilities, which are significant for smart service provision. These capabilities were than divided into three main categories, such as technical equipment, internal readiness and knowledge and involvement of customers. As was mentioned by Winter (2003) that portfolio of capabilities can be seen in two levels, the base level and above the base level, it is possible to admit that capabilities mentioned by respondents are mostly from above the base level category, it means level of dynamic capabilities described by Teece (2018). These capabilities lead to innovation of company offering and are not routine at all. Especially internal readiness and knowledge and involvement of customers and ability to adopt new approaches through company offering is often hard to fulfil.

The category of capabilities focused on technical equipment is mentioned by Marquardt (2017) as one prerequisite for smart services. Many challenges for smart services are perceived in the area, such as lack of technology, data analytics and knowledge or experienced staff.

The findings from the interviews are very similar to findings of Grubic and Peppards (2016), where factors enable the benefits of smart service provision are firstly operating centers and support from complementary data sources, process and structures, secondly skills, experience and knowledge and thirdly support from customers.

\section{Managerial Implications}

The findings illustrate the main capabilities for smart service provision seen by respondents from electrotechnical companies. During interviews was heard often that technical equipment is the first and most important capabilities for starting with smart service provision. However, internal readiness is still the crucial. As many of respondents (mostly owners of companies) mentioned that for beginning with smart services, their enthusiasm for smart service provision was very essential and smart service provision could not begin.

Technical equipment and also knowledge and involvement of customers are seen as important capabilities for smart service provision, but without internal readiness in companies, mainly in top management, they are not sufficient.

Therefore, the list of recommendations for companies, which want to start with smart service provision was created and already discussed in some electrotechnical companies 
which already have adopted smart services. For this paper only part focused on important conditions for internal recommendations was chosen. Conditions for internal recommendations are the following ones:

- enthusiasm of management,

- management belief in this area, future vision and benefits,

- management must be active, persistent and resilient, not discouraged,

- think smart services seriously and strategically (this is a long way),

- have an R\&D department that will take care of the development (external sources can also be used),

- subsequently training the staff on the benefits (especially sales representative), applications and smart services implementation,

- ensuring safety,

- providing appropriate infrastructure and tools (e.g. cloud rental) to develop smart services.

\section{Conclusion}

Smart services based on smart product are very topical for researchers and also for manufacturers. Therefore, it is crucial to wide discuss this area. The paper describes capabilities for smart service provision from theoretical view and also from the view of manufacturers. It analyses which capabilities are significant for smart service provision and tries to divide them in some categories. To address the research objective, a qualitative multi-case study was conducted among seven Czech electrotechnical SMEs, which have already started providing smart service development.

The findings revealed that respondents mentioned wide range of possible capabilities, which could be divided into three main categories, such as technical equipment, internal readiness and knowledge and involvement of customers. These findings are also in line with above mentioned theory and the first theoretical and managerial implications were prepared. However other investigation is necessary because of the limited number of cases, where it is impossible to generalize the findings.

Future quantitative research in small and medium manufacturers is already in the progress. The aim is to verify the findings from the qualitative research described also in this paper.

\section{Acknowledgement}

Eva Tomaskova contributed in the research, which was held in sixty electrotechnical SMEs companies in the Czech Republic, South Moravian Region in 2014. 


\section{References}

ALLMENDINGER, G., LOMBREGLIA, R., 2005. Four strategies for the age of smart services. Harvard business review. 83(10), 131.

BAINES, T. et al., 2017. Servitization: revisiting the state-of-the-art and research priorities. International Journal of Operations \& Production Management. 37(2), 256-278.

BEVEUNGEN, D., MATZNER, M., JANIESCH, Ch., 2017. Information systems for smart services. 781-787.

BIEHL, M., PRATER, E., MCINTYRE, J. R., 2004. Remote repair, diagnostics, and maintenance. Communications of the ACM. 47(11), 100-106.

BORGMEIER, A., 2002. Schlußbetrachtung. In: Teleservice im Maschinen-und Anlagenbau. Deutscher Universitätsverlag. 209-217.

BRAX, S. and JONSSON, K., 2009 Developing integrated solution offerings for remote diagnostics: a comparative case study of two manufacturers. International Journal of Operations \& Production Management. 29(5), 539-560.

EISENHARDT, K. M. and GRAEBNER, M. E., 2007. Theory building from cases: Opportunities and challenges. Academy of management journal. 50(1), 25-32.

GARCIA, E., et al., 2004. A new industrial cooperative tele-maintenance platform. Computers \& Industrial Engineering. 46(4), 851-864.

GEBAUER, H., GUSTAFSSON, A., WITELL, L., 2011. Competitive advantage through service differentiation by manufacturing companies. Journal of business research. 64(12), 12701280.

GRUBIC, T. and PEPPARD, J., 2016. Servitized manufacturing firms competing through remote monitoring technology: An exploratory study.Journal of Manufacturing Technology Management. 27(2), 154-184.

KLEIN, M. M., 2017. Design Rules for Smart Services. PhD Thesis. University of St. Gallen.

KÜSSEL, R., et al., 2000. "TeleService" a customer-oriented and efficient service? Journal of Materials Processing Technology. 107(1), 363-371.

LAINE, T., PARANKO, J., SUOMALA, P., 2010. Downstream shift at a machinery manufacturer: the case of the remote technologies. Management Research Review. 33(10), 980-993.

LEE, J., 1998. Teleservice engineering in manufacturing: challenges and opportunities. International Journal of Machine Tools and Manufacture. 38(8), 901-910.

LEE, J., KAO, H., YANG, S., 2014. Service innovation and smart analytics for industry 4.0 and big data environment. Procedia Cirp. 16, 3-8.

LEVRAT, E., IUNG, B., CRESPO MARQUEZ, A., 2008. E-maintenance: review and conceptual framework. Production Planning \& Control. 19(4), 408-429.

MANUFACTURER. Manufacturing 2020: How far is your business looking into the future? [online]. 2018 [cit. 2018-07-16]. Retrieved from https://www.themanufacturer.com/articles/manufacturing-2020-how-far-is-yourbusiness-looking-into-the-future/ 
MARQUARDT, K., 2017. Smart services-characteristics, challenges, opportunities and business models. In: Proceedings of the International Conference on Business Excellence. De Gruyter Open. 789-801.

NEU, W. A. and BROWN, S. W., 2008. Manufacturers forming successful complex business services: Designing an organization to fit the market. International Journal of Service Industry Management. 19(2), 232-251.

OLIVA, R. and KALLENBERG, R., 2003. Managing the transition from products to services. International journal of service industry management. 14(2), 160-172

PORTER, M. E. and HEPPELMANN, J. E., 2014. How smart, connected products are transforming competition. Harvard Business Review. 92(11), 64-88.

ROWLEY, J., 2006. An analysis of the e-service literature: towards a research agenda. Internet research. 16(3), 339-359.

TEECE, D., 2007. Explicating dynamic capabilities: the nature and microfoundations of (sustainable) enterprise performance. Strategic Management Journal. 28(13), 1319-1350.

TEECE, D., 2018. Business models and dynamic capabilities. Long Range Planning. 50, 4049.

VANDERMERWE, S. and RADA, J., 1988. Servitization of business: adding value by adding services. European management journal. 6(4), 314-324.

Winter, S., 2003. Understanding dynamic capabilities. Strategic Management Journal. 24(10), 991-995.

WISE, R. and BAUMGARTNER, P., 1999. Go downstream. Harvard business review. 77.5.

WÜNDERLICH, N. V., et al., 2015. "Futurizing" smart service: implications for service researchers and managers. Journal of Services Marketing. 29(6/7), 442-447.

\section{Contact address of the author(s):}

Ing. Lucie Kaňovská, Ph. D. Institute of Management, Faculty of Business and Management, Brno University of Technology, Kolejní 2906/4, Brno, Czech Republic, E-mail: kanovska@fbm.vutbr.cz

https://doi.org/10.36708/Littera_Scripta2019/2/3 